\title{
Cement Percent Effect on the Shear and Interface Strength of Remolded Cement Treated Sand
}

\author{
Zahraa N. Rashied \\ Department of Geotechnical Engineering, Faculty of Engineering, Koya University, Koya KOY45, Kurdistan Region - F.R. Iraq
}

\begin{abstract}
This research aims to simulate the behavior of remolded cement treated poorly graded sand in term of shear and interface strength using the direct shear test. Different percentages of cement up to $15 \%$ by weight are added to the soil samples. Compacted cement treated soil samples are prepared at the optimum moisture content and left for $\mathbf{2 8}$ days in the humidity room then distributed to use them for the remolding samples preparation. The shear strength parameters for both cases soil to soil interface and concrete to soil interface are predicted, where the results show that the interface strength parameters are higher than the shear strength parameters of the remolded soil samples. The increase in cement percent increases the cohesion $(C)$ of the treated soil, whereas the interface cohesion $\left(\mathrm{C}_{\text {int. }}\right)$ has a maximum value at $10 \%$ of added cement, and the maximum percent between cohesion $\left(\mathrm{C}_{\mathrm{int}}\right)$ and soil cohesion (C) is of $76.2 \%$ at $0 \%$ added cement. Moreover, the results show an increase in the interface angle of friction $(\delta)$ and a decrease in the angle of friction $(\phi)$ as the percent of cement increases. The maximum percent between interface angle $(\delta)$ and angle of friction $(\phi)$ is $63.5 \%$ at $15 \%$ of the added cement. The hardened cement in the remolded case adheres to sand grains and works as soil grains with different sizes that lead to changes in the shear properties of the soil.
\end{abstract}

Index Terms-Cement treated sand, Interface strength, Remolded soil, Shear strength.

\section{INTRODUCTION}

Placement of materials having different properties adjacent to each other led to generating the interface zone which can make it the weakest point of the overall system in terms of shear strength compared to that of neighboring materials. Soil structure interfaces are commonly controlling the overall design and stability of civil engineering structures.

Soils consist of particles with different sizes and properties which make them easy to undergo large deformation when being loaded (both compression and shear). Structural elements that made from concrete or steel can be treated as solid continuum materials compared with soils. The interfaces between these two types of materials are of unique

ARO-The Scientific Journal of Koya University

Vol. X, No.1 (2022), Article ID: ARO.10805, 4 pages DOI: $10.14500 /$ aro. 10805

Received: 24 March 2021; Accepted: 29 January 2020

Regular research paper: Published: 19 February 2022

Corresponding author's e-mail: zahraa.noori@koyauniversity.org Copyright (C) 2022 Zahraa N. Rashied. This is an open access article distributed under the Creative Commons Attribution License. properties. Many researchers were interested in finding the relationship between the soil angle of internal friction $(\phi)$ and the interface friction angle $(\delta)$.

Potyondy (1961) and Acar, et al. (1982) studied the effect of soil density on the interface angle of friction using direct shear apparatus with the sand on the top of concrete pad; they concluded that the interface angle increased as the density increased and the interface angle equal to the angle of internal friction. Uesugi, et al. (1990) used simple shear with the sand on top of the test material, their finding was same as that observed by Potyondy (1961) and Acar, et al. (1982). Sliding the material over the sand using direct shear mode was conducted by Broms (1963) and Noorany (1985) and they stated that the influence of sand density on the interface angle of friction is negligible. Recording the particle displacement at the interface between steel and sand using speed camera observed by $\mathrm{Hu}$ and $\mathrm{Pu}$ (2001), they stated that the shear failure is accompanied by strain softening and strong normal dilatancy. Feng (2012) used the multi-functional 3-D shear test equipment developed by Hou, et al. (2008) to observe the effect of different types of coarse-grained soils, structural plates and boundary conditions and loading conditions on the mechanism of interface between soil and structure. Their results (Hou, et al., 2008 and Feng, 2012) showed deeply constitutive interface laws between granular soil and structure. There were limited studies that discussed the effect of remolding on the behavior of cement treated soils, most of them were related to the effect of remolding for fine grain soils (Watabe, et al., 2016 and Suganya and Sivapullaiah, 2020). The present study is the first of its kind that discusses the effect of remolding on the strength and interface strength (soil-concrete) of cement treated granular soils. The effect of cement as treating material by dry weight of cohesion less soil up to $15 \%$ on the interface friction angle and cohesion between concrete and the compacted remolded cement treated soil will be discussed in this study by comparing them with the angle of internal friction and cohesion of the remolded cement treated samples. It is believed that the result observed in this study will be useful when the remolding of cement treated soils is required in some sits previously treated by cement.

\section{Materials and Testing Program}

For the purpose of predicting the effect of remolding on the behavior of cement treated granular soil in term of cohesion 
and internal angle of friction (soil - soil) and interface cohesion and angle of friction between remolded cement treated soil and concrete (soil - concrete), granular soil samples were predicted from Drbandikhan, Sulaymaniyah (Kurdistan ReligionIraq) used for this purpose, whereas the cement that used as improvement agent was ordinary Portland cement.

The soil mechanic laboratory of Koya University was used to conduct the material properties and shear tests, according to ASTM (American Society for Testing and Materials, 2020). Grain size analysis of the tested soil was carried out according to ASTM D 422, 2020, the grain size distribution for the soil used in this study is as shown in Fig. 1. The grain size analysis show that the percent passing from sieve No. 200 was about $1.9 \%$ whereas the percent of sand was of $75.4 \%$, the coefficients of uniformity and curvature were 3.3 and 0.7 , respectively, so that soil classified as poorly graded sand (SP) according to the Unified Soil Classification System (USCS) (ASTM Test Designation D-2487). Specific gravity test was carried out on virgin soil according to ASTM D 854-00; the test result reflected that the specific gravity for the tested soil was 2.6. Compaction tests were confirmed according to ASTM D 698, 2020. The maximum dry density and optimum moisture content represent important parameters to preparing the samples for the direct shear test. Fig. 2 shows the variation of water content with dry density; the results showed that the maximum dry density was $1.71 \mathrm{kN} / \mathrm{m}^{2}$ whereas the optimum moisture content was $14 \%$.

Compacted soil samples at different cement content $(0,5,10$, and $15 \%$ ) were prepared at optimum moisture continent and left for 28 day in the humidity room. After the 28 days, the samples

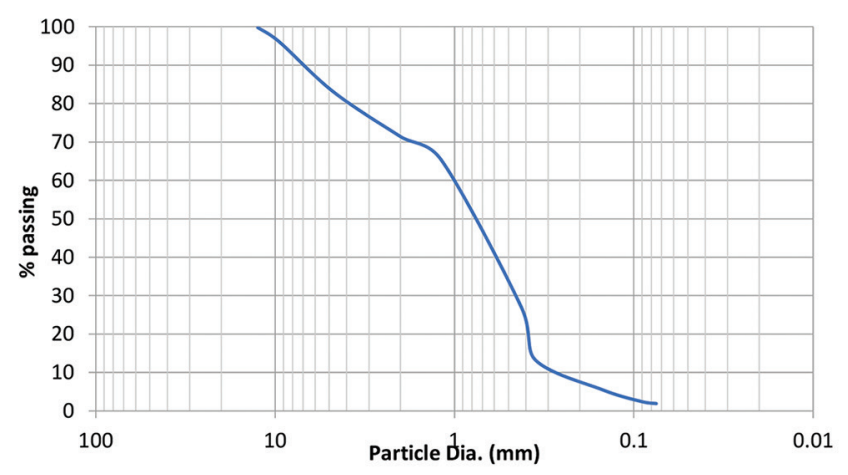

Fig. 1. Grain size analysis of the tested soil ( $0 \%$ of cement).

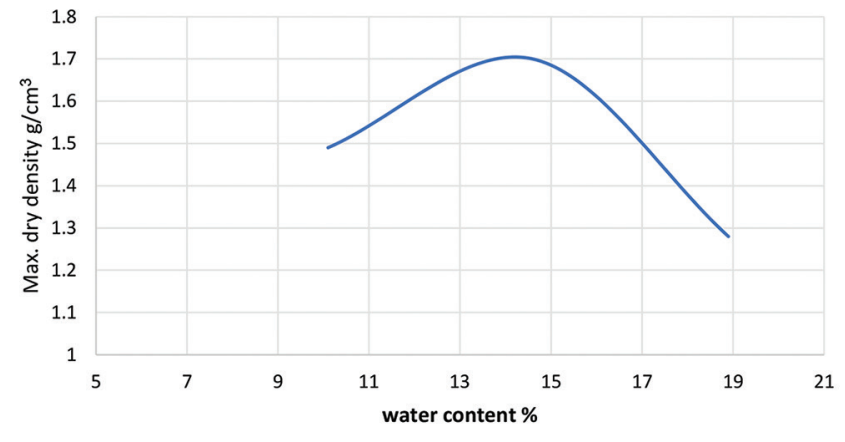

Fig. 2. Variation of maximum dry density with water content (standard compaction test). disturbed to make them suitable for preparing remolded samples. Shear strength parameters of the virgin soil and also of all the soil mixed with different cement content were determined by direct shear tests on remolded samples obtained from compaction at optimum moisture content based on ASTM D 3080, 2020. The test is run several times for verticalconfining stresses of $70 \mathrm{kN} / \mathrm{m}^{2}, 138 \mathrm{kN} / \mathrm{m}^{2}$, and $206 \mathrm{kN} / \mathrm{m}^{2}$.

To prepare compacted soil samples for direct shear test purpose, the remolded soil passed from sieve No.16. Some soil placed in the mold and compacted in three equal layers. The number of drops of the plastic rammer that used to compact the soil was 25 drop per layer. The drops were applied at a uniform rate not exceeding around $1.5 \mathrm{~s}$ per drop, and the rammer provided uniform coverage of the specimen surface so that sample density must be represent the max density achieved from the standard compaction test.

For evaluating the shear strength parameters in case of sand-concrete interface, concrete interface element with dimension of $(6 \times 6 \times 1) \mathrm{cm}$ was prepared for this purpose. The mix proportions were (1 cement:3 aggregate) and the water - cement ratio (w/c) was 0.4 . Direct shear test made by sliding the concrete element over the sand.

\section{RESULTS}

A direct shear device used to determine the shear strength parameter of treated remolded compacted soil with different

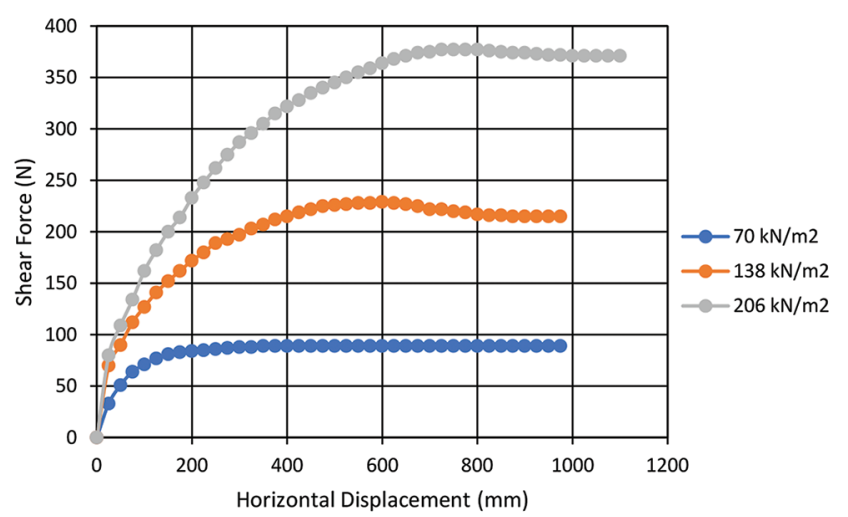

Fig. 3. Variation of shear force with horizontal displacement (10\% of Cement).

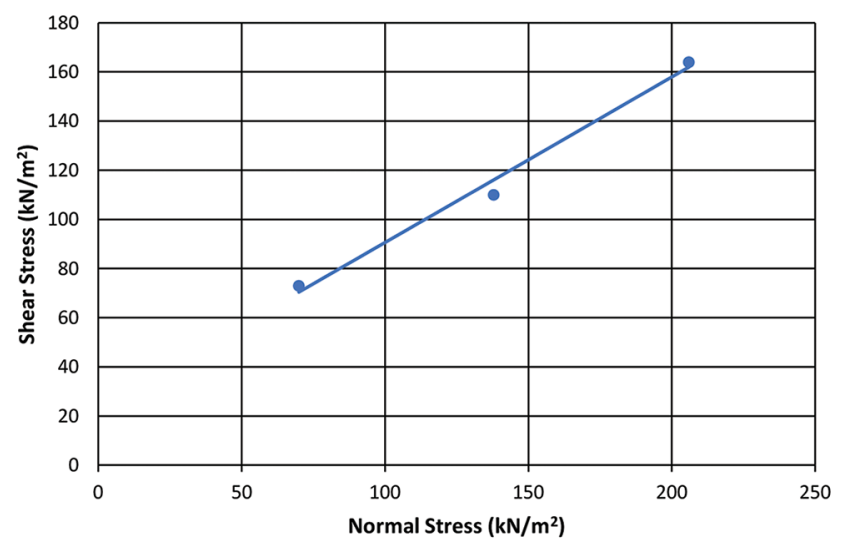

Fig. 4. Evaluation of angle of friction and cohesion of soil (10\% cement). 
TABLE I

RESULTS SUMMARY

\begin{tabular}{|c|c|c|c|c|c|c|}
\hline$\%$ of cement & $\begin{array}{c}\text { Cohesion }(\mathrm{C}) \\
\left(\mathrm{KN} / \mathrm{m}^{2}\right)\end{array}$ & Friction angle $(\varphi)$ (degree) & $\begin{array}{l}\text { Interface cohesion } \\
\left(\mathrm{C}_{\text {int. }}\right)\left(\mathrm{kNlm}^{2}\right)\end{array}$ & interface friction angle $(\delta)$ (degree) & Friction* $(\%)$ & Cohesion** (\%) \\
\hline 5 & 18.21 & 34.83 & 21.27 & 36.88 & 5.9 & 16.8 \\
\hline 15 & 24.82 & 30.1 & 29.72 & 49.2 & 63.5 & 19.7 \\
\hline
\end{tabular}

${ }^{*}$ Friction $(\%)=(\delta-\varphi) / \varphi,{ }^{*}$ Cohesion $(\%)=\left(\mathrm{C}_{\text {int }}-\mathrm{C}\right) / \mathrm{C}$

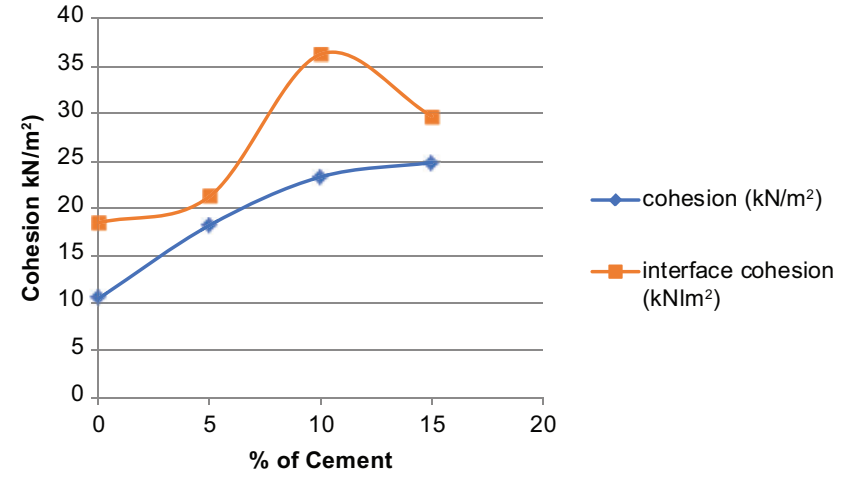

Fig. 5. Variation of the soil cohesion and interface cohesion with cement percent.

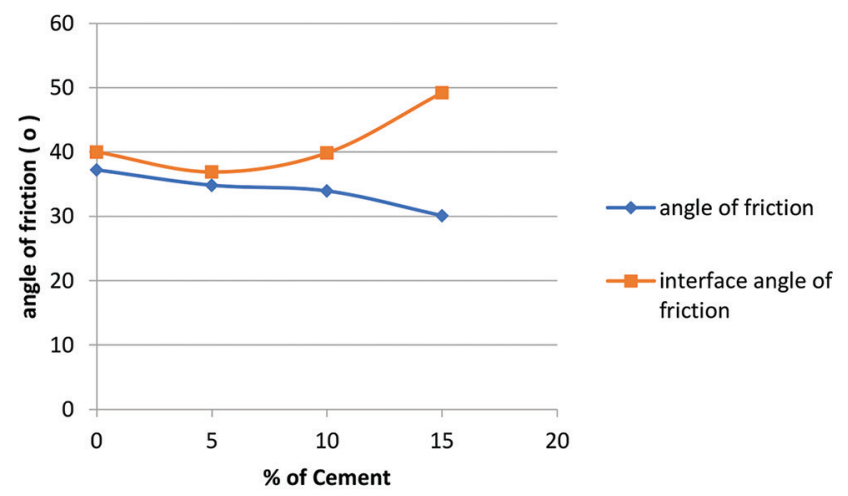

Fig. 6. Variation of the friction angle and interface friction angle with cement percent.

percent of cement up to $15 \%$. Low strain rate of $0.01 \mathrm{~mm} / \mathrm{min}$ were used to prevent rapid failure of the samples and as a result the observed data can simulate the exact behavior. The direct shear test was running three times for each percent to conform the observed results. The angle of friction and cohesion for both cases soil to soil interface and concrete to soil interface were predicted to find the ratio between the shear strength parameters at the same cement contamination percent for both cases. From the results of the shear stress versus the horizontal displacement, the maximum shear stress is obtained for a specific vertical confining stress. After the test is run several times for various vertical-confining stresses $\left(70 \mathrm{kN} / \mathrm{m}^{2}, 138 \mathrm{kN} / \mathrm{m}^{2}\right.$, and $\left.206 \mathrm{kN} / \mathrm{m}^{2}\right)$, the angle of friction and cohesion were obtained. Fig. 3 shows that the variation of shear force with horizontal displacement for $10 \%$ of cement soil sample as example whereas a plot of the maximum shear stresses versus the vertical (normal) confining stresses for
$10 \%$ of cement shown if Fig. 4. Same procedure repeated for all samples treated by cement up to $15 \%$ for both cases (soil - soil) and (concrete - soil) interface. The summary of the results was as concluded in Table I.

As a conclusion from the predicated results of the direct shear test of the treated remolded poorly graded sand according to adding of different percent of cement up to $15 \%$, Fig. 5 shows the variation of soil cohesion (C) and interface cohesion $\left(\mathrm{C}_{\text {int. }}\right)$ verse the increase in the percent of cement, the results showed that as the percent of cement increase the cohesion of soil increase, whereas the interface cohesion tends to increase then decrease its value beyond $10 \%$ of cement contaminations, the maximum percent cohesion percent was $76.2 \%$ according to $0 \%$ contamination as shown in Table I. Whereas Fig. 6 show the variation of the angle of friction $(\phi)$ and interface friction angle $(\delta)$ of the soil with cement percent, the results showed that as the percent of cement increase the angle of friction decrease, whereas the interface angle of friction increase, the maximum percent between interface angle of friction and angle of friction was $63.5 \%$. As a conclusion interface cohesion $\left(\mathrm{C}_{\text {int. }}\right)$ and internal angle of friction $(\delta)$ are more than cohesion $(\mathrm{C})$ and angles of friction $(\phi)$ of the untreated and remolded treated soil. It is believed that the cement in the remolded case adhered to sand particles and worked as soil grains with different sizes and as a result, the properties of the remolded soil changed as measured in term of cohesion and angle of friction.

\section{CONCLUSION}

The predicated results from the direct shear test of the untreated and treated remolded poorly graded sand according to adding of different percent of cement up to $15 \%$ reflect the following conclusions:

1. The results show that the interface cohesion $\left(\mathrm{C}_{\text {int }}\right)$ and interface friction angle $(\delta)$ are more than cohesion $(\mathrm{C})$ and angles of friction $(\phi)$ of the untreated and remolded treated soil whereas most of the previous studies concluded that interface friction angle and angles of friction are equal $(\delta=\phi)$.

2. The increase in cement percent led to increase in the cohesion of soil $(\mathrm{C})$, whereas the interface cohesion $\left(\mathrm{C}_{\text {int }}\right)$ tends to increase then decrease its value beyond $10 \%$ of cement contaminations, the maximum percent between interface cohesion and soil cohesion was $76.2 \%$ according to $0 \%$ cement contamination.

3. The results also show that as the percent of cement increase the angle of friction decrease, whereas the interface angle 
of friction increase, and the maximum percent between interface angle of friction and angle of friction was $63.5 \%$ at $15 \%$ of cement contamination.

4. It is believed that the cement in the remolded case adhered to sand particles and worked as soil grains with different sizes and as a result the properties of the soil changed as measured in term of cohesion and angle of friction.

\section{REFERENCES}

Acar, Y.B., Durgunoglu, H.T. and Tumay, M.T., 1982. Interface properties of sand. Journal of Geotechnics, 108, pp.648-654.

ASTM, 2020. Annual Book of American Standards for Testing and Materials, Part 8. Vol. 4. ASTM, United States.

Braja, M.D. and Sobhan, K., 2014.In: Shortt CM, editor. Principles of Geotechnical Engineering. $8^{\text {th }}$ ed. Christopher M. Shortt.

Broms, B.B., 1963. Discussion on bearing capacity of piles in cohesionless soils. Journal of the Soil Mechanics Division of the ASCE, 89, pp.125-126.

Feng, D.K., 2012. Three-Dimensional Constitutive Laws, Mechanism and Model of Gravel-Structure Interfaces, PhD Thesis, Tsinghua University, Beijing.
Hou, W.J., 2008. Research on monotonic and cyclic behavior and constitutive model of three-dimensional soil-structure interface, PhD thesis, Tsinghua University, Beijing.

Hu, L.M. and Pu, J.L., 2001. Experimental study on mechanical characteristics of soil-structure interface. Chinese Journal of Geotechnical Engineering, 23, pp.431-435.

Hu, L.M. and Pu, J.L., 2003. Application of damage model for soil-structure interface. Computers and Geotechnics, 30, pp.165-183.

Noorany, I., 1985. Side Friction of Piles in Calcareous Sands, Proceedings of the $11^{\text {th }}$ International Conference of Soil Mechanics and Foundation Engineering, Cambridge, USA, pp.12-16.

Potyondy, J.G., 1961. Skin friction between various soils and construction materials. Geotechnique, 11, pp.831-853.

Suganya, K. and Sivapullaiah, P.V., 2020. Compressibility of remolded and cement-treated Kuttanad soil. Soils and Foundations, 60, pp.697-704.

Uesugi, M., Kishida, H. and Uchikawa, Y., 1990. Friction between dry sand and concrete under monotonic and repeated loading. Soils and Founds, 30, pp.115-128.

Watabe, Y., Kaneko, T. and Wantanabe, Y., 2016. Cement mix proportion for treated soils recycled from a cement treated soil. Japanese Geotechnical Society Special Publication, 4, pp.168-172. 